\author{
Research Paper
}

\title{
A COMPARISON OF SIX METHODS USED TO EVALUATE APPARENT THERMAL DIFFUSIVITY FOR SOILS (IĞDIR REGION, EASTERN TURKEY)
}

\author{
RESAT MIKAIL, ELMAN HAZAR*, ALI FARAJZADEH, ERHAN ERDEL, AND FARIZ MIKAILSOY
}

\begin{abstract}
The objective of this work is to investigate the influence of boundary conditions at depth soil on the development of methods to determine the soil s apparent thermal diffusivity based on solution of inverse problems of a heat-transfer equation. Experimental investigations were carried out to establish the influence of boundary conditions at depth in soil on the solution of inverse problems of modeling of heat transfer in soils. For this purpose, 1 soil profile in the land at different depths $(x=0,5,10,15,20,40,60 \mathrm{~cm})$ thermal sensors (Temperature recorder Elitech RC-4) have been installed to measure soil temperatures depending on time and depths. Based on these data, the apparent thermal diffusivity in soils was calculated using the classical (layered) and proposed (point) methods developed for the case with one and two harmonics, and they were compared and the calculated characteristics were compared with the experimental results. It was found that the proposed point methods best reflect the movement of heat in the soil profile.
\end{abstract}

MSC(2010): 35M2; 11P70.

Keywords: soil thermal properties, heat conduction model, apparent thermal diffusivity, boundary conditions, comparison of methods.

\section{Introduction and Background}

Soil thermal properties are important in agriculture and metrological applications. The soil thermal properties depend on its physical and hydro-mechanical properties, such as degree of saturation, dry density, solid fraction in the soil, organic matter content, the mineral composition of the soil, the water content in the soil, and the porosity filled with air $[1,3-5,7,13,17,20,21]$. Soil thermal properties such as heat capacity $\left(C_{v}\right)$, apparent thermal diffusivity $(\kappa)$, thermal conductivity $(\lambda)$, damping depth $(d)$, and heat absorptions $(b)$, principally control soil temperature and soil heat flow. Determination of these parameters is important to understand behavior of soil thermal regime and manage soil temperature at field scale. Kim et al. (2018) reported that there are several in-situ methods for measuring thermal properties, including needle probes, divided bar, borehole relaxation, non-linear fitting, thermal gradients pulse, and estimation from thermal gradients. The generally accepted method for assessing the apparent thermal diffusivity of soil is the methods described in the works of Chudnovsky (1947), Carslaw, and Jaeger (1959) and et al [6-8, 10-19,22]. These methods are based from observed soil temperature: on measuring the temperature of the day's surface and temperature at various depths of the soil. All of these researchers and others noted

Date: Received: November 30, 2020, Accepted: May 20, 2021.

${ }^{*}$ Corresponding author. 


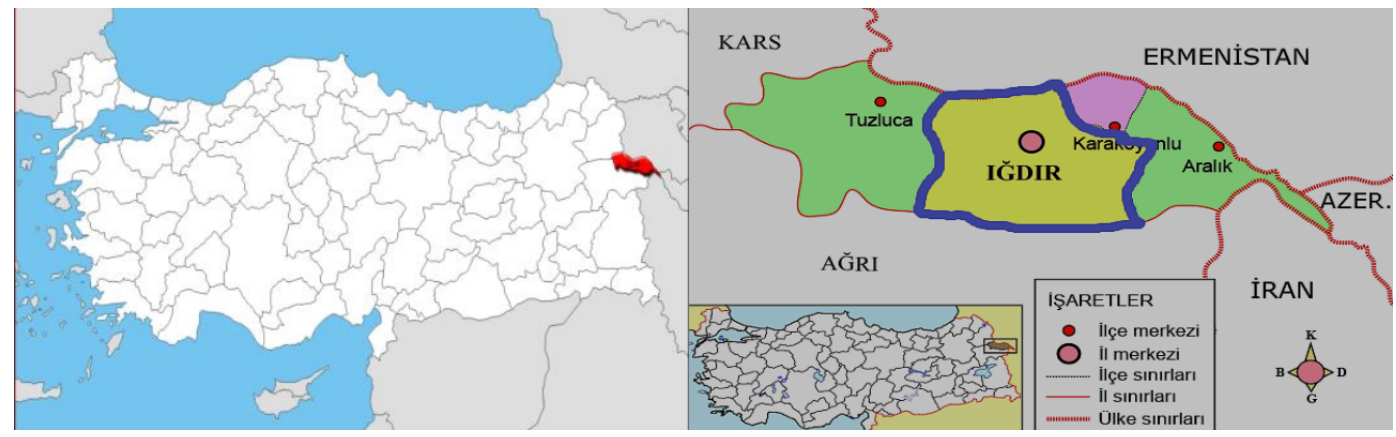

FiguRE 1. Location of study area

that most of these models are based on solutions of the one-dimensional heat equation with constant diffusion. (Gao et al., 2009; Carslaw \& Jaeger, 1959; Horton et al., 1983; Kaganov \& Chudnovsky, 1953; Kolmogorov, 1950; Mikayilov \& Shein, 2010; Nerpin \& Chudnovskii, 1967; Tong et al., 2017; Wang et al., 2010). In modeling heat-transfer processes in soil, there is a need for analysis of solution of heat transfer equations, since for practical calculations of a thermal regime, use can be made of approximate solutions that have a simpler form and possess a sufficient accuracy, which must be,as far as possible, in fuller conformity with the physical picture of the processes of heat propagation in soil. To this end, it is expedient to make an analysis of the impact on heat transfer in soil using simplifications most frequently used in practice and to assess the influence of boundary conditions, individual terms, and coefficients of differential equations, and the effects of the dimensions of the region on the process being described. The accuracy and adequacy of physically substantiated models are determined first of all by experimental information on physical, hydrophysical, and physiochemical properties of individual layers (horizons) of soils and their conditions on the upper and lower boundaries. The objective of this study was investigate the infl uence of boundary conditions in the soil depth under natural conditions on the development of methods to determine the soil s apparent thermal diffusivity based on solution of inverse problems of a heat-transfer equation. In this case, the thermal conductivity and diffusion coefficient were predicted on the undisturbed soil profile by four different classical and two improved methods, and the results were compared.

\section{Materials and Methods}

The research was carried out by opening a profile at $2 \mathrm{~m}$ length and $60 \mathrm{~cm}$ width in the land of Iğdır University Agricultural Application and Research Center located within the borders of Melekli Municipality of Iğdır Province (Figure 1). The geographical location of the study area is between $39,1^{\circ}-39,5^{\circ}$ East longitude and $44^{\circ}-44,2^{\circ}$ North latitude. Located at $850 \mathrm{~m}$ above sea level, the Igdir region covers approximately $3.588(1.479) \mathrm{km}^{2}$ plain exhibiting a non-uniform characteristics in terms of topography. Thermal sensors are used for measuring and recording soil temperature in the soil profile with the depths of $0,5,10,15,20,40$ and $60 \mathrm{~cm}$.

In this study, soil temperature was measured with a portable thermal Sensor (Elitech RC-4 Mini temperature data logger- See Figure 2). The sensor registers and stores temperature measurements in its memory. Recorded temperature degrees are stored directly and can be downloaded by users via data cable. 


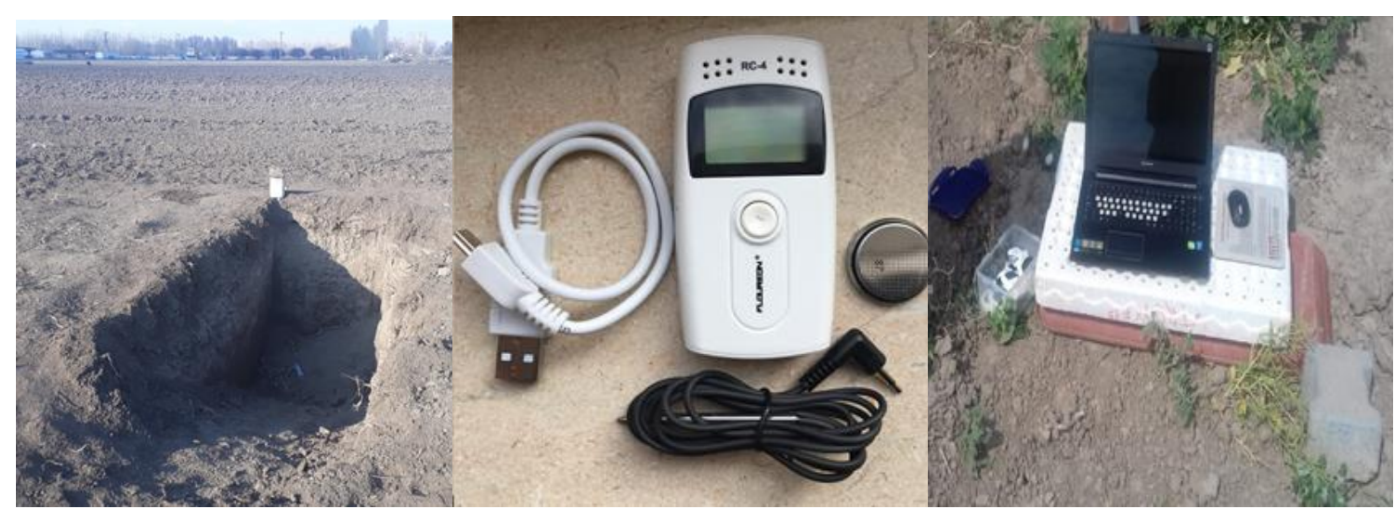

Figure 2. Placing the thermel sensors (Elitech RC-4 Mini temperature data logger) in soil profile

\section{Selection of a Model of Heat Transfer in Soil}

The one-dimensional distribution of the temperature field in an isotropic medium is described by the following classical equation of heat conduction [2-5]

$$
C_{v}(Z, t) \frac{\partial T(z, t)}{\partial t}=\frac{\partial}{\partial z}\left[\lambda(z, t) \frac{\partial T(z, t)}{\partial t}\right], \quad(z, t) \in(0, t) \times(0<z<L)
$$

where $T(z, t)$ is the soil temperature ( $\mathrm{K}$ or ${ }^{\circ} \mathrm{C}$ ) at depth $z(m), t$ is time (sec); $C_{v}$ is the volumetric heat capacity of the soil $\left(\mathrm{J} \cdot \mathrm{m}^{-3} \cdot \mathrm{K}^{-1)}\right.$ and $C_{v}=\rho_{b} . C_{m}$, where $\rho_{b}$ is the soil bulk density $\left(\mathrm{kg} \cdot \mathrm{m}^{-3}\right) ; C_{m}$ is the specific heat capacity $\left(\mathrm{J} \cdot \mathrm{kg}^{-} 1 . \mathrm{K}\right) ; \lambda$ is the thermal conductivity $\left(\mathrm{W} \cdot \mathrm{m}^{-1} \cdot \mathrm{K}^{-1}\right)$, which can vary with soil moisture content. Assuming that a soil is vertically homogeneous, and that $\mathrm{Cv}$ and $\lambda$ are independent of depth and time, Equation (3.1) becomes [1-22]

$$
\frac{\partial T}{\partial t}=\kappa \frac{\partial^{2} T}{\partial z^{2}}
$$

where $\kappa\left(=\lambda / C_{v}\right)$ is the apparent soil thermal diffusivity $\left(\mathrm{m}^{2} / \mathrm{s}\right)$.

\section{Identification of Boundary Conditions of Heat Transfer in Soil}

The equation (3.1) must be solved analytically or numerically to find the temperature change at a given time $t$ and at the depth $z$ of soil. To solve equation (3.1), initial and boundary conditions are needed that reflect the natural process of heat transfer in the soil. The initial conditions correspond to the state of the variable at the zero (initial) time moment. For the theoretical description of the quasi-stationary regime problem (e.g., the daily or annual variation of the soil temperature), the initial condition is absent (so-called problems without an initial condition).

To study the influence of boundary conditions in modeling the transfer of heat in soil, we must set initial and boundary conditions. It is well known that the infl uence of the initial condition has no effect, in practice, on the distribution of the soil temperature at the instant of observation.

If the instant of time of interest is distant from the initial one, it makes sense to disregard the initial conditions, since their influence on the process becomes even weaker with time, 
particularly, in the case of periodic formulation of the problem, e.g., of daily or annual variation in the soil temperature [2-4,12-17]. The surface boundary condition of the first kind is written in the common form

$$
T(0, T)=\varphi(t)
$$

where the function $\varphi(t)$ describes the changes in the soil surface temperature with time; the analytical form of the function should be determined in advance.

$$
T(0, t)=T_{0}+\sum_{j=1}^{m} T_{j} \cos \left(j . \omega t+\epsilon_{j}\right),
$$

where $T_{0}$ is the average daily (or annual) temperature of the active soil surface; $T_{j}$ is the amplitude of the wave at the surface level for the jth harmonic; $j$ is the index of the harmonic in the series; $\omega=2 \pi / \tau_{0}$ is the angular daily (or annual) frequency; $\tau_{0}$ is the temperature wave period (days or years), for $\tau_{0}=24$ hours: $\omega=7,2710^{-5}(\mathrm{rad} / \mathrm{s}) ; \epsilon_{j}$ is the phase angle of the wave at the surface level for the $j$-th harmonic (radians); $m$ is the harmonic number. The lower boundary condition is:

$$
T(x \rightarrow \infty, t)=T_{0}
$$

or

$$
\partial T(x=L, t) / \partial x=0
$$

\section{Solution of the Direct Problem of Heat Transfer in Soil}

We should consider the solution of a problem in which the boundary conditions are specified and there are no initial conditions. The solution of (3.2) with boundary conditions (4.2) and (4.3) in dimensionless variables is of the form $[2,3]$.

$$
T(y, t)=T_{0}+\sum_{j=1}^{m} T_{j} \exp \left(-b_{j} y\right) \cos \left(j \bar{\omega} \tau+\alpha_{j}\right),
$$

where

$$
y=\frac{z}{L}, \quad \tau=\frac{K t}{L^{2}}, \quad \bar{\omega}=\frac{\omega L^{2}}{\kappa}, \quad b_{j}=L \sqrt{j \frac{\pi}{\tau_{0} \kappa}}, \quad \alpha_{j}=\epsilon_{j}-b_{j} y
$$

This problem was already studied by Fourier; it was first applied by Kelvin for the determination of the temperature variation in the soil of Edinburgh [3, pp. 78].

As correctly noted in $[12,13]$, when performing practical calculations, it is not possible to set the values of soil temperature at infinity as input data, since they are unknown. And it is impossible to measure it. Therefore, instead of $T(\infty, t)$, the temperature should be set at a certain depth $L$, starting from which for $x \geq L$ the quantity $T(x, t)=$ const or $\partial T(L, t) / \partial x=0$. Thus, condition (4.4) more corresponds to the real conditions than boundary condition (4.3) $[12,13]$. Therefore, one should also consider the boundary value problem (3.2), (4.2), and (4.2). The solution to this problem in dimensionless variables is as follows $[12,13]$.

$$
T(y, t)=T_{0}+\sum_{j=1}^{m} \Phi_{j}\left(y, b_{j}\right) \cdot \cos \left[j \bar{\omega} \tau+\epsilon_{j}-\Psi_{j}\left(y, b_{j}\right)\right]
$$


The functions $\Phi_{j}$ and $\Psi_{j}$ are determined by:

$$
\Psi_{j}\left(b_{j}, y\right)=T_{j} \sqrt{\frac{\mathbf{c h}\left(\mathbf{d}_{\mathbf{j}}\right)+\cos \left(\mathbf{d}_{\mathbf{j}}\right)}{\mathbf{c h}\left(\mathbf{2} \mathbf{b}_{\mathbf{j}}\right)+\cos \left(\mathbf{2} \mathbf{b}_{\mathbf{j}}\right)}}, \quad \Phi_{j}\left(y, b_{j}\right)=\arctan \left[\frac{P_{2 j}\left(y, b_{j}\right)}{P_{1 j}\left(y, b_{j}\right)}\right]
$$

where

$$
\left\{\begin{array}{l}
P_{1 j}=\mathbf{c h}\left(q_{j}\right) \cos \left(b_{j} y\right)+\mathbf{c h}\left(b_{j} y\right) \cos \left(q_{j}\right) \\
P_{2 j}=\mathbf{s h}\left(q_{j}\right) \sin \left(b_{j} y\right)+\mathbf{s h}\left(b_{j}\right) \sin \left(q_{j}\right)
\end{array}, \quad d_{j}=2 b_{j}(1-y), q_{j}=b_{j}(2-y)\right.
$$

\section{Solution of the Inverse Problem of Heat Transfer in Soil}

6.1. Classical methods for determining the coefficient of apparent thermal diffusion. On the basis of analytical solutions (5.1) of equation (3.2), various authors derived formulas for determining the apparent thermal diffusion coefficient [2-4, 8, 10, 13]. These methods are based on measuring the temperature of the day's surface and the temperature variation with depth soil.Below are the classic algorithms that are developed for the case when the daily variation of temperature on the soil surface is represented by one and two harmonics 1. Amplitude algorithm (Carslaw and Jaeger, 1959):

$$
\kappa=\frac{\pi}{\tau_{0}} \cdot \frac{\left(z_{2}-z_{1}\right)^{2}}{\ln ^{2}\left[\frac{T_{\max }\left(z_{1}\right)-T_{\min }\left(z_{1}\right)}{T_{\max }\left(z_{2}\right)-T_{\min }\left(z_{2}\right)}\right]}
$$

\section{Phase algorithm (Nerpin and Chudnovskii, 1967):}

$$
\kappa=\frac{\pi}{\tau_{0}}\left(\frac{z_{1}-z_{2}}{\phi_{2}-\phi_{1}}\right)^{2}
$$

\section{Arctangent algorithm (Kaganov and Chudnovsky, 1953):}

$$
\kappa=\frac{\pi\left(z_{2}-z_{1}\right)^{2}}{\tau_{0} \cdot \arctan ^{2}\left\{\frac{\left[T_{1} z_{1}-T_{3} z_{1}\right]\left[T_{2} z_{2}-T_{4} z_{2}\right]-\left[T_{2} z_{1}-T_{4} z_{1}\right]\left[T_{1} z_{2}-T_{3} z_{2}\right]}{\left[T_{1} z_{1}-T_{3} z_{1}\right]\left[T_{1} z_{2}-T_{3} z_{2}\right]-\left[T_{2} z_{1}-T_{4} z_{1}\right]\left[T_{2} z_{2}-T_{4} z_{2}\right]}\right\}}
$$

\section{Logarithmic algorithm (Kolmogorov, 1950):}

$$
\kappa=\frac{4 \pi\left(z_{2}-z_{1}\right)^{2}}{\tau_{0} \cdot \ln ^{2}\left\{\frac{\left[T_{1} z_{1}-T_{3} z_{1}\right]^{2}+\left[T_{2} z_{1}-T_{4} z_{1}\right]^{2}}{\left[T_{1} z_{2}-T_{3} z_{2}\right]^{2}+\left[T_{2} z_{2}-T_{4} z_{2}\right]^{2}}\right\}}
$$

where; $\tau_{0}$ in the algorithms (6.1) period of heat wave, i.e. being the period of the fundamental cycle $\left(24 \mathrm{~h}\right.$ for daily temperature); $T_{\min }(z)$ and $T_{\max }(z)$ are the minimum and maximum temperature values during the measurement at the depths of $z=z_{1}$ and $z=z_{2}$ respectively; $\epsilon_{1}$ and $\epsilon_{2}$ in the algorithms (6.2) are the initial phases of the soil temperature at the depths of $z=z_{1}$ and $z=z_{2}$ respectively; $T_{i}\left(z_{1}\right)$ and $T_{i}\left(z_{2}\right)$ in the algorithms (6.3)-(6.4) are the soil temperature values at the depths $z=z_{1}$ and $z=z_{2}$, respectively, at the time moment $t_{i}=i \tau_{0} / 4(\mathrm{i}=1,2,3,4)\left(\right.$ for our example $\tau_{0}=24 \mathrm{~h}$ and $t_{1}=6, t_{2}=12, t_{3}=18$ and $t_{4}=24 \mathrm{~h}$ ) 
6.2. Improved methods for determining the coefficient of apparent thermal diffusion. In contrast to the above algorithms, we continued to develop new methods that take into account the actual process of heat transfer in the soil. To do this, we used the solution(5.3) derived for a semi-bounded soil thickness $[12,13]$. These suggested methods for calculating the apparent thermal diffusivity of soil $\mathrm{k}$ are presented below.

1. Suggested algorithm-1 (Mikayilov and Shein, 2010):

$$
\kappa_{i}=\frac{\pi}{\tau_{0}} \frac{2\left(z_{i}\right)^{2}}{\ln ^{2} \frac{\left[T\left(z_{i}, t_{1}\right)-T\left(z_{i}, t_{3}\right)\right]^{2}+\left[T\left(z_{i}, t_{2}\right)-T\left(z_{i}, t_{4}\right)\right]^{2}}{4 T_{a}^{2}}}
$$

2. Suggested algorithm-2 (Mikayilov and Shein, 2010):

$$
\kappa_{i}=\frac{\pi}{\tau_{0}} \cdot\left(\frac{L}{b_{i}^{*}}\right)^{2}
$$

where; $T\left(z_{i}, t_{j}\right)$ in the algorithm (6.5) are the soil temperature values at the depth $z=z_{i}$, at the time at the time moment $t_{j}=j \tau_{0} / 4(\mathrm{j}=1,2,3,4)$ (for our example $\tau_{0}=24 \mathrm{~h}$ and $t_{1}=6$, $t_{2}=12, t_{3}=18$ and $t_{4}=24 \mathrm{~h}$ ). Using solution (5.3) for one harmonic, i.e. $m=1$, first, for an arbitrary dimensionless depth and time $t_{j}=j \tau_{0} / 4(j=1,2,3,4)$, the following four equations are written:

$$
T\left(y, t_{i}\right)=T_{0}+\Phi(y, b) \cdot \cos \left(i \frac{\pi}{2}+\alpha\right), \quad(i=\overline{1,4})
$$

since it takes place $\bar{\omega} \tau_{i}=\frac{\omega L^{2}}{\kappa} \cdot \frac{\kappa}{L^{2}} t_{i}=\omega t_{i}=\frac{2 \pi}{\tau_{0}} \cdot i \cdot \frac{\tau_{0}}{4}=\frac{\pi}{2} \cdot i$ and then we have: $\bar{\omega} \tau_{i}=\frac{\pi}{2} \cdot i$ After some transformations of equations (6.7) we have:

$$
\sum_{i=1}^{2}\left[T\left(y, t_{i}\right)-T\left(y, t_{i+2}\right)\right]^{2}=4 \Phi^{2}(y, b)
$$

Taking into account the notation (5.4)-(??) for the function $\Phi_{1}\left(y, b_{1}\right)$ and $\Psi_{1}\left(y, b_{1}\right)$ in equality (6.8), we have the following expressions, which correspond to the boundary conditions (4.3) and (4.4):

$$
\text { (6.9) } M_{\exp }(y, b)=\frac{\sum_{i=1}^{2}\left[T\left(y, t_{i}\right)-T\left(y, t_{i+2}\right)\right]^{2}}{4 T^{2}}=\frac{c h[2 b(1-y)]+\cos [2 b(1-y)]}{c h(2 b)+\cos (2 b)}=M_{c a l}(y, b)
$$

The definition of $\kappa$ using formula (6.9) is carried out by the method of selecting on a computer the value of the parameter $b_{1}^{*}$ from the condition of the coincidence of the value of the left side and the right side calculated from the initial data, that is, $M_{\exp }(y, b)$.

From the relationship $b^{*}=L \sqrt{\pi / \tau_{0} \kappa}$, we find the value of the apparent thermal diffusivity coefficient $\kappa$ at a depth of $z=z_{*}$, which is equal to

$$
\kappa_{i}=\frac{\pi}{\tau_{0}} \cdot\left(\frac{L}{b_{i}^{*}}\right)^{2}
$$

where $\mathrm{b}^{*}$ are the values of the parameter $\mathrm{b}$, at which $\left|M_{\text {exp }}-M_{c a l}\right| \leq 10^{-5}$ 
A COMPARISON OF SIX METHODS USED TO EVALUATE APPARENT THERMAL DIFFUSIVITY ... 57

\begin{tabular}{cccccccc}
\hline $\begin{array}{c}\text { Depth (z) } \\
\mathrm{m}\end{array}$ & Clay & $\begin{array}{c}\text { Slit } \\
\%\end{array}$ & Sand & $\begin{array}{c}\text { BD } \\
\mathrm{kg} \mathrm{m}^{-3}\end{array}$ & $\begin{array}{c}\text { OM } \\
\%\end{array}$ & $\theta$ & $C_{v}$ \\
\hline $\mathbf{0 - 1 0}$ & 28.60 & 32.10 & 39.80 & 0.9743 & 1.40 & 0.2406 & 1757.5904 \\
$\mathbf{2 0 - 2 5}$ & 25.50 & 29.50 & 45.10 & 1.0491 & 2.35 & 0.2584 & 1901.3979 \\
$\mathbf{3 0 - 3 5}$ & 14.20 & 19.60 & 66.30 & 1.1581 & 3.07 & 0.2672 & 2033.1646 \\
$\mathbf{5 0 - 6 0}$ & 22.45 & 33.35 & 44.20 & 1.3431 & 1.60 & 0.1870 & 1820.3163 \\
$\mathbf{0 - 6 0}$ & 22.69 & 28.64 & 48.85 & 1.1312 & 2.11 & 0.2383 & 1878.1173 \\
\hline
\end{tabular}

TABLE 1. Some physical and chemical properties of research soil

Comparison of Methods The performance of four methods was evaluated by Pearson's Correlation Coefficient $(r)$, Coefficient of Determination $\left(R^{2}\right)$, Root Mean Squared Error $(\mathrm{RMSE}, \sigma)$, Mean Absolute Percentage Error (MAPE, A), and Theil's U Statistic (UII).

\section{Results and Discussion}

The main thermal characteristics of the soil are the coefficients of volumetric heat capacity $\left(C_{v}\right)$, thermal conductivity $(\lambda)$, thermal diffusivity $(\kappa)$, thermal absorptive (assimilability), heat flow on the soil surface $(Q)$ and the damping depth $(d)$ of diurnal temperature waves, which are calculated by the following formulas $[5,20]$

$$
\begin{array}{r}
C_{v}=\rho_{b} . C_{m . s}+C_{v, w} \cdot \theta=\rho_{b}\left[C_{m . o r g} \cdot \frac{m_{\text {org }}}{m}+C_{m . m i n} \cdot\left(1-\frac{\left.m_{\text {org }}\right)}{m}\right]+\rho_{w} \cdot C_{w} \cdot \theta\right. \\
\lambda=\kappa \cdot C_{\nu}, \quad d=\sqrt{\tau_{0} \kappa / \pi}, \quad e=C_{v} \sqrt{\kappa}=\sqrt{\lambda C_{v}}
\end{array}
$$

where, $C_{m, s}$ is the specific heat of the soil's solid part, $J /\left(\mathrm{kg}^{\circ} \mathrm{C}\right) ; \rho_{b}$ is the soil bulk density, $\mathrm{kg} / \mathrm{m}^{3} ; C_{v, w}$ is the volumetric heat capacity of the soil moisture equal to 4186.6106 $\mathrm{kJ} /\left(\mathrm{m}^{3 \circ} \mathrm{C}\right) ; \mathrm{Cw}$ is the specific heat of water, $4186.6106 \mathrm{~kJ} /\left(\mathrm{kg}^{\circ} 0 \mathrm{C}\right) ; \rho_{w}$ is the water density, $\mathrm{kg} / \mathrm{m}^{3} ; \theta$ is the volumetric moisture content $\left(\mathrm{m}^{3} / \mathrm{m}^{3}\right) ; C_{m \text {,org }}$ and $C_{m, \text { min }}$ are the specific heats of the organic and mineral components of the soil solid phase, respectively, $\mathrm{J} /\left(\mathrm{kg}^{\circ} \mathrm{C}\right)$; $m_{\text {org }}$ is the mass of soil organic matter, $\mathrm{kg} ; m$ is the soil mass $(\mathrm{kg}) ; m_{\text {org }} / m$ is the content of organic substance in soil. Vertical changes of soil properties in soil profile and soil column are depicted in Table 1. Figure 3 gives the daily behavior of surface and soil temperatures at different depths.

To determine the parameters of the soil s active surface $\left(T_{0}, T_{i}\right.$ and $\left.\epsilon_{i}\right)$, we adopted one and two harmonics in condition (4.2). Using the measurement results for $x=0$, that is, $T(x=$ $\left.0, t_{i}\right)$ and using the least squares method, we determined the parameters of the temperature distribution of the surface of in studied soils.

Table 2 gives results of calculation of the parameters, and also statistical characteristics of approximation between the initial data and the data computed from (4.2) for $n=1$ and $n=2$. As can be seen from Table 2 , the introduction of the second harmonic makes it possible to determine with high accuracy the parameters of the temperature distribution on the soil surface. Mean values for soil thermal diffusivity $(\kappa)$, thermal conductivity $(\lambda)$ and damping depth $(d)$ calculated by amplitude, phase, arctangent and logarithm methods are given in Table 3. After determining the values of the thermal diffusivity $\kappa$, using the classical and improves formulas (6.1)-(6.2), the values of $T(z, t)$ for the depths of $5,10,15,20,40$, and $60 \mathrm{~cm}$ 


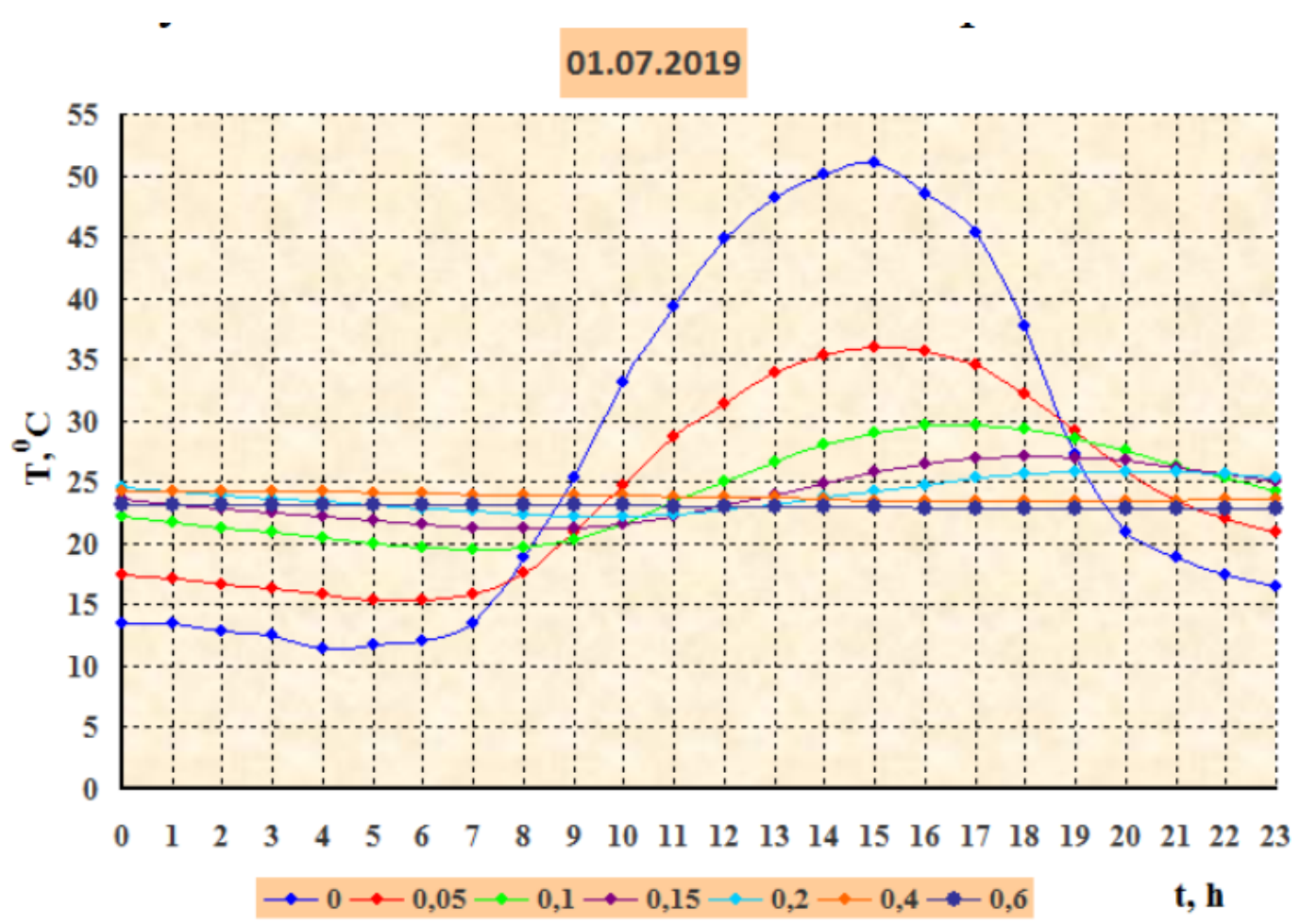

FIgURE 3. The hourly behavior of surface and soil temperatures at different depths

\begin{tabular}{clcccc}
\hline $\mathcal{N}_{\overline{0}}$ & The parameters of soil surface & \multicolumn{3}{c}{ number of harmonics } \\
& & \multicolumn{2}{c}{$\mathrm{m}=1$} & \multicolumn{2}{c}{$\mathrm{m}=2$} \\
\cline { 3 - 6 } 1 & Mean Temperature at soil surface $\left(T_{0}\right),{ }^{\circ} C$ & $T_{0}$ & 26.8488 & $T_{0}$ & 26.8488 \\
2 & Amplitude of oscillationsof the soil surface temperature $\left(T_{i}\right),{ }^{\circ} C$ & $T_{1}$ & 19.5764 & $T_{2}$ & 5.5732 \\
3 & Phase shift & $\epsilon_{1}$ & 2.4929 & $\epsilon_{2}$ & -1.0678 \\
\hline $\mathcal{N}_{\overline{0}}$ & Statistical approximation parameters & & & \\
\hline 1 & Coefficient of Determination, $\%$ & $\mathbb{R}^{2}$ & 91.77 & $\mathbb{R}^{2}$ & 99.21 \\
2 & Root Mean Squared Error (RMSE) $T$ in $t$ & $\sigma$ & 4.54 & $\sigma$ & 1.48 \\
3 & Mean Absolute Percentage Error (MAPE), \% & $\mathrm{A}$ & 18.73 & $\mathrm{~A}$ & 3.91 \\
4 & Normalized Standard Error or Theil's U Statistic & $\mathrm{UII}$ & 0.1359 & $\mathrm{UII}$ & 0.0421 \\
\hline
\end{tabular}

TABLE 2. Parameters of the field soils surfaces and model performance

were calculated for the soil temperature. A comparison of numerical calculations revealed that improved methods 1 and 2, with a comparison with all classical methods, give satisfactory results (see Table 4)). Therefore, when modeling heat transfer in soils, it is necessary to take into account conditions of the second kind on the lower boundary. And to determine the parameter thermal diffusivity it is advisable to use Method 2. 
A COMPARISON OF SIX METHODS USED TO EVALUATE APPARENT THERMAL DIFFUSIVITY ... 59

\begin{tabular}{ccccccc}
\hline $\mathcal{N}_{\overline{0}}$ & Type of methods & $\begin{array}{c}C_{v} \\
\mathrm{KJ} /\left(\mathrm{m}^{3} \cdot{ }^{\circ} \mathrm{C}\right)\end{array}$ & $\begin{array}{c}10^{-6} . \kappa \\
\mathrm{m}^{2} / \mathrm{s}\end{array}$ & $\begin{array}{c}\lambda \\
\mathrm{W} /\left(\mathrm{m} .{ }^{\circ} \mathrm{C}\right)\end{array}$ & $\begin{array}{c}d \\
\mathrm{~m}\end{array}$ & \begin{tabular}{c}
$e$ \\
Classical Methods \\
\hline \multicolumn{7}{c}{$\mathrm{h}^{0.5} /\left(\mathrm{m}^{2} .{ }^{\circ} \mathrm{C}\right)$}
\end{tabular} \\
\hline 1 & Amplitude & 1878.1173 & 0.5416 & 1.0172 & 0.1220 & 23.0362 \\
2 & Phase & 1878.1173 & 6.2780 & 11.7908 & 0.4155 & 78.4300 \\
3 & Arctangent & 1878.1173 & 13.2986 & 24.9764 & 0.6048 & 114.1498 \\
4 & Logarithm & 1878.1173 & 0.4889 & 0.9183 & 0.1160 & 21.8878 \\
\hline 5 & Improved Methods \\
\hline 6 & Methods-5 & 1878.1173 & 0.2878 & 0.5405 & 0.0890 & 16.7917 \\
\hline
\end{tabular}

TABLE 3. The mean values of the thermal diffusivity $(\kappa)$, thermal conductivity $(\lambda)$, damping depth $(\mathrm{d})$ and heat absorptivity (e) of studies soils, calculated by six different methods.

\begin{tabular}{ccccccccc}
\hline $\mathbf{z}$ & \multicolumn{4}{c}{$\sigma$} & \multicolumn{4}{c}{$A$} \\
\hline \multicolumn{4}{c}{ Numbering of methods } & \multicolumn{3}{c}{ Numbering of methods } \\
\hline $\mathrm{m}$ & 1 & 4 & 5 & 6 & 1 & 4 & 5 & 6 \\
\hline 0.05 & 3.876 & 3.836 & 3.940 & 1.560 & 12.534 & 12.196 & 11.876 & 3.841 \\
0.10 & 3.927 & 3.780 & 3.448 & 2.068 & 12.301 & 11.661 & 10.980 & 4.645 \\
0.15 & 3.728 & 3.610 & 3.408 & 2.603 & 11.727 & 11.717 & 12.284 & 6.175 \\
0.20 & 3.364 & 3.279 & 3.168 & 2.457 & 11.667 & 11.721 & 12.006 & 5.745 \\
0.40 & 3.151 & 3.160 & 3.158 & 1.640 & 12.586 & 12.657 & 12.664 & 3.739 \\
0.60 & 3.992 & 3.993 & 3.993 & 2.219 & 16.596 & 16.596 & 16.597 & 5.302 \\
\hline
\end{tabular}

TABLE 4. Values of parameters and A for comparing methods 1-6. RMSE $(\sigma)$-Root Mean Squared Error, MAPE $(A)$-Mean Absolute Percentage Error.

\section{CONCLUSIONS}

When modeling heat transfer in soils, it is necessary to take into account conditions of the second kind on the lower boundary. And to determine the parameter thermal diffusivity, it is advisable to use Method 2. In fact, at certain depths, convective heat transfer is absent and the heat flux is zero, so it is necessary to accept the boundary conditions of the second kind. If the depth of profile is relatively small, then it is advisable to use Method 1, since this method also takes into account the values of the amplitude of the soil surface.

\section{REFERENCES}

[1] D. Assouline, N. Mohajeri, A. Gudmundsson, J.L Scartezzini, Combining fourier analysis and machine learning to estimate the shallow-ground thermal diffusivity in Switzerland, J. IEEE International Symposium on Geoscience and Remote Sensing (IGARSS), 19 Valencia, Spain, pp 1144-1147, 2018. https://doi.org/10.1109/IGARSS.2018.8517938

[2] H.J. Carslaw, and J.C. Jaeger, Conduction of heat in solids (2nd edition), Oxford University Press, New York, $510 \mathrm{p}, 1959$.

[3] A.F. Chudnovsky, Physics of heat transfer in soil, Gostekhizdat, 220 p, 1948 (in Russian).

[4] A.F. Chudnovsky, Thermophysical characteristics of dispersed materials. State publishing house of physical and mathematical literature, 1962 
[5] D. A. De Vries, Thermal properties of soil, Physics of Plant, North-Holland Publishing Company, Amsterdam, pp. 210--235, 1963

[6] Z. Gao, L. Wang, and R. Horton, Comparison of six algorithms to determine the soil thermal diffusivity at a site in the Loess Plateau of China, Hydrol. Earth Syst. Sc. Discus. 6(2), 2247-74, 2009.

[7] R. Horton, P.J. Wierenga, and D.R. Nielsen, Evaluation of methods for determining the apparent thermal diffusivity of soil near the surface, Soil Sci. Soc. Am. J., 47, 25-32, 1983.

[8] M. A. Kaganov, and A.F. Chudnovsky, On the determination of the thermal conductivity of the soil. Izv. Acad. Sci. USSR. Geogr., 2, 183-191, 1953 (in Russian).

[9] H. Kim, K.K. Lee, and J. Lee, Comparison of Carslaw and Jaeger method and finite element method to estimate temperature of soil in Antarctica, Episodes. 41(1): 51-58, 2018, https://doi.org/10.18814/epiiugs/2018/v41i1/018005

[10] A. N. Kolmogorov, On the question of determining the coefficient of thermal diffusivity of the soil, $I z v$. Acad. Sci. USSR. Geogr.Geophys., 2(14), 97-99, 1950 (in Russian).

[11] M. Lahoori, S. Rosin-Paumier, Y. Jannot, A. Boukelia, F. Masrouri, Thermal energy storage in embankments: Investigation of the thermal properties of an unsaturated compacted soil, E3S Web of Conferences, Vol. 205, p. 07011, 2020. https://doi.org/10.1051/e3sconf/202020507011

[12] F.D. Mikayilov, About one solution of the equation of heat conductivity in soil. International Conference on 'The fifth scientific readings J.P. Bulashevicha. Deep structure. Geodynamics. Thermal field of the Earth. Interpretation of geophysical fields'. Scientific publications, pp. 319-323, (6 - 10 July, 2009, Yekaterinburg, Russia).

[13] F.D. Mikayilov,and E.V. Shein, Theoretical bases the experimental methods definitions of thermal diffusivity of soil. Eurasian Soil Science, 43(5), 536-544, 2010.

[14] F.D. Mikailsoy, On the influence of boundary conditions in modeling heat transfer in soil, Journal of Engineering Physics and Thermophysics, 90(1): 67-79, 2017. https://doi.org/10.1007/s10891-017-1540$y$

[15] F. Mikailsoy, E. Shein, Comparison of four classical algorithms to determine the apparent thermal diffusivity of heavy clay soil in field and laboratory column experiments. IOP Conference Series: Earth and Environmental Science, Vol. 368, Conference 1, 012033, pp. 1-11. 2019, https://doi.org/10.1088/1755$1315 / 368 / 1 / 012033$

[16] F.D. Mikailsoy, E. Erdel, E.Hazar, R. Mikail, On the influence of boundary conditions at depth in modeling heat transfer in soil, The Proceedings of Conference on: III. International Eurasian Agriculture And Natural Sciences Congress. pp: 105-112 (17-20 October, 2019, Antalya, Turkey), 2019, http://agrieurasia.com/EN/Home

[17] S.V. Nerpin, and A.F. Chudnovskii, Soil physics, (Moscow: Nauka) p 584, 1967 (in Russian)

[18] P. Rajeev and J.Kodikara, Estimating apparent thermal diffusivity of soil using field temperature time series, (Geomechanics and Geoengineering, 11(1): 28-46, 2015. https://doi.org/10.1080/17486025.2015.1006266

[19] B. Tong, Z. Gao, R. Horton, and L. Wang, Soil apparent thermal diffusivity estimated by conduction and by conduction-convection heat transfer models, J. Hydrometeorol. 18(1), 109-118, 2017.

[20] E.V. Shein, Theories and methods of soils physics, Moscow: Grif and K, 2017 (in Russian).

[21] W.R. Van Wijk, and D.A. De Vries, Periodic temperature variations in a homogeneous soil, In: W R Van Wijk (Editor) Physics of plant environment (Amsterdam, North Holland Publishing Company), $2 n d$ edn. pp 102-143, 1963.

[22] L. Wang, Z. Gao, and R. Horton, Comparison of six algorithms to determine the soil thermal diffusivity at a site in the Loess Plateau of China, Soil Sci. 175(2), 51-60, 2010. 
A COMPARISON OF SIX METHODS USED TO EVALUATE APPARENT THERMAL DIFFUSIVITY $\ldots 61$

(Resat Mikail) FACulty of Science And Art, IĞdir University, IĞDiR, 76000, Turkey.

(Elman Hazar) Department of Applied Mathematics, Faculty of Science And Art, IĞdir UniverSITY, IĞDIR, 76000, TURKEY.

Email address: elman.hazar@igdir.edu.tr

(Ali Farajzadeh) Department of Mathematics, Science Faculty, Razi University, Kermanshah 67149, IRAN

Email address: farajzadehali@gmail.com

(Erhan Erdel) Department of Soil Science and Plant Nutrition, Faculty of Agriculture, IĞdir UnIVERSity, IĞDIR, 76000, TURKEY.

Email address: erhan.erdel@igdir.edu.tr

(Fariz Mikailsoy) Department of Soil Science and Plant Nutrition, Faculty of Agriculture, IĞDIR UNIVERSITY, IĞDIR, 76000, TURKEY.

Email address: fariz.m@igdir.edu.tr 